\title{
Pengembangan Wilayah Berbasis Subsektor Pertanian Hortikultura di Kecamatan Plaosan Kabupaten Magetan
}

\author{
Sigit Dwi Kuncoro ${ }^{1}$ \\ Kementerian Pekerjaan Umum \\ Jakarta, Indonesia
}

\begin{abstract}
Abstrak: Kecamatan Plaosan merupakan salah satu kecamatan di Kabupaten Magetan yang perekonomianya ditopang oleh kegiatan sektor pertanian. Salah satu sektor pertanian yang menjadi andalan adalah pertanian hortikultura. Namun terdapat permasalahan yang mengindikasikan sektor pertanian hortikultura belum maksimal didalam peningkatan ekonomi masyarakat di Kecamatan Plaosan. Data BPS menunjukan Kecamatan Plaosan diantara 18 (delapan belas) kecamatan di Kabupaten Magetan dengan jumlah penduduk miskinnya (pra sejahtera) terbanyak kedua setelah Kecamatan Panekan, dan ada kecengerungan peningkatan penduduk miskin dari tahun 2008 s.d 2011 yang rata-rata 1,5\% setiap tahunnya. Penelitian ini bertujuan untuk mengetahui pengembangan wilayah berbasis subsektor pertanian hortikultura di Kecamatan Plaosan Kabupaten Magetan dengan menggunakan metode kuantitatif deskriptif dengan tiga analisis. Pertama, analisis karakteristik dan potensi wilayah. Kedua, analisis faktor-faktor pendorong dan penghambat. Ketiga, analisis pengaruh kegiatan pertanian hortikultura bagi peningkatan kesejahteraan petani dan kontribusinya didalam pengembangan wilayah di Kecamatan Plaosan Kabupaten Magetan. Hasil penelitian ini adalah sebagai berikut: pertama, ketersediaan lahan pertanian, tenaga kerja, masihlah sangat potensial untuk dikembangkan. Kedua, kegiatan usaha pertanian tersebut masih belum memberikan pengaruh yang sangat besar bagi kesejahteraan petani dengan indikator Nilai Tukar Petani/ NTP rata-rata di Kecamatan Plaosan adalah 100,96. Angka ini jauh dari rata-rata NTP sektor pertanian hortikultura nasional yaitu sebesar 109,34. Ketiga, faktor yang paling berpengaruh mempengaruhi hasil NTP adalah ketersediaan bahan dan alat secara lokal, dimana masih belum terpenuhinya secara maksimal bahan dan alat secara lokal tersebut. Sektor pertanian hortikultura di Kecamatan Plaosan dapat dikembangkan sebagai motor penggerak perekonomian masyarakat serta menjadi sektor unggulan yang mendorong pembangunan wilayah di Kecamatan Plaosan. Untuk itulah perlu upaya peningkatan NTP petani dan pengoptimalan kinerja sektor pertanian hortikultura melalui: (1) pembenahan subsektor hulu petanian, dalam hal ini terkait dengan penyediaan bibit unggul, pupuk, dan obat-obatan. (2) Peningkatan subsektor penunjang terkait dengan kegiatan yang menghasilkan dan menyediakan jasa yang dibutuhkan seperti pemasaran, irigasi, transportasi, penelitian pengembangan, penyuluhan dan konsultasi.
\end{abstract}

Kata kunci: Pengembangan wilayah, Subsektor pertanian hortikultura.

Abstract: Plaosan distric is one of the Magetan regency where its economic activities supported by agricultural activities. The leading agricultural sector is horticulture. But there are problems that indicate the agricultural sector is not maximized in the improvement of the local economy in the Plaosan district. BPS note's shown the District Plaosan among 18

\footnotetext{
${ }^{1}$ Korespondensi Penulis: Kementerian Pekerjaan Umum, Jakarta, Indonesia Email: sigitdwikuncoro@gmail.com
} 


\section{Pengembangan Wilayah Berbasis Subsektor Pertanian Hortikultura Di Kecamatan Plaosan}

(eighteen) districts in Magetan has the number of poor people (pre-prosperous) the second largest after the Panekan District, and there is an increasing trend of poor people from 2008 till 2011 with an average of $1.5 \%$ per year. This study aims to determine the regional development of agriculture-based on horticultural subsector in Plaosan district using quantitative descriptive with three analysis. First, analysis of the characteristics and potential of the area. Second, the analysis of the factors driving and inhibiting. Third, analysis of the effect of horticultural farming activities for improving the welfare of farmers and their contribution in the development of the region in Plaosan district. The results of this study are as follows: First, the availability of agricultural land, labor, still very potential to be developed. Second, agricultural activities have not yet had significant impact on the welfare of farmers which shown by indicators of Farmers Exchange / NTP average in Plaosan district is 100.96. This figure is far from the average exchange rate of the national horticultural farmers agricultural sector that is equal to 109.34. Third, the most influential factor affecting the results of the exchange rate of farmers is the availability of local materials and equipment, which still have not been fulfilled. Horticulture sector in the Plaosan district can be developed as the driving force of the economic society as well as being the leading sectors that encourage development in the Plaosan. Therefore, we need an effort to increase the exchange rate of farmers and horticulture performance optimization through: (1) improvement of upstream agricultural sub-sector, in this case related to the provision of seeds, fertilizers, and drugs. (2) Improvement of support subsector associated to generating activities and providing necessary services such as marketing, irrigation, transportation, research development, extension and consultancy.

Keywords: horticulture, regional development.

\section{Pendahuluan}

Kecamatan Plaosan adalah Salah satu kecamatan yang merupakan sentra pertanian hortikultura di Kabupaten Magetan. Sebagai salah satu sektor yang potensial untuk dikembangkan, subsektor pertanian hortikultura di Kecamatan Plaosan Kabupaten Magetan merupakan sektor yang dapat menjadi leading sector (sektor unggulan) dan juga economic base (ekonomi basis) pada wilayah ini. Didalam pengembangan wilayah yang salah satu pemicunya oleh kegiatan aktivitas ekonomi yang dapat menjadi motor bagi pertumbuhan ekonomi didasarkan pada potensi lokal yang dimiliki oleh suatu wilayah. Ambardi dan Prihawantoro (2002), faktor pendukung yang mempengaruhi perkembangan suatu wilayah adalah faktor internal yang meliputi potensi sumber daya alam, manusia dan teknologi atau metode penanganan yang tepat dalam memanfaatkan sumber daya yang ada tanpa mengesampingkan fungsi ekologis suatu wilayah, serta faktor eksternal seperti kebijakan dari pemerintah daerah yang mempunyai hierarki lebih tinggi yang membatasi wilayah dalam suatu batasan administratif. Keunggulan potensi sumberdaya alam khususnya didaerah perdesaaan adalah sektor pertanian seperti kecamatan Plaosan dengan sektor pertanian hortikulturanya yang potensial untuk dikembangkan menjadi motor penggerak perekonomian masyarakat. Namun dalam perkembanganya belum optimal untuk dijadikan sebagai leading sector (sektor unggulan) bagi pertumbuhan eonomi masyarakat. Meskipun secara statistik laju pertumbuhan PDRB sektor pertanian kabupaten Magetan selalu terlihat positif, begitu juga dengan kecamatan Plaosan, namun belum memberikan dampak signifikan bagi kemajuan pengembangan wilayah di Kabupaten Magetan. Ada beberapa kendala terkait pengembangan sektor pertanian yang secara umum terdapat 8 (delapan) permasalahan pokok sebagai kendala dalam upaya Pengembangan pertanian di Magetan yaitu ketersediaan benih unggul, ketersediaan pupuk yang memadai, ketersediaan air, rusaknya jaringan irigasi, minimnya alat mekanisasi pertanian, jatuhnya harga saat panen, lemahnya permodalan kelompok tani, dan sempitnya 
kepemilikan lahan. Dari data jumlah keluarga pra sejahtera di Kabupaten Magetan secara umum masih tinggi dan cenderung mengalami kenaikan selama tahun 2006 sampai 2010 sebesar rata-rata 1,5\%. Dari delapan belas Kecamatan yang ada di Kabupaten Magetan, Kecamatan Plaosan adalah Kecamatan yang jumlah keluarga miskinnya terbesar kedua setelah Kecamatan Panekan. Hal ini menunjukan bahwa meskipun potensi sektor pertanian di Kecamatan Plaosan cukup potensial namun belum memberikan dampak signifikan bagi kesejahteraan masyarakat dan pembangunan wilayah di Kecamatan Plaosan.

\section{Metode Penelitian}

Penelitian ini adalah Deskriptif Kuantitatif. Metode pengumpulan data yang digunakan dalam penelitian ini adalah Observasi lapangan, Survey sekunder, Survey primer dilakukan memberikan kuisioner. Kuisioner diberikan kepada Petani. dan didukung dengan wawancara mendalam dengan responden. Dalam penelitian ini penentuan sampel dilakukan dengan menggunakan purposive sampling. Adapun jumlah responden dalam penelitian ini adalah 80 (delapan puluh) rumah tangga petani di 14 (empat belas) desa di Kecamatan Plaosan. Analisis penelitian ini adalah analisis desktiptif kuantitatif dengan berdasarkan data sekunder time series tahun 2009-2012, Analisis Skala linkert, Analisis Deskriptif kuantitatif dari data penghitungan NTP dan analisis regresi berganda.

\section{Gambaran Umum}

Kecamatan Plaosan merupakan kecamatan yang terletak di bagian barat kabupaten Magetan dan berada pada ketinggian antara $500 \mathrm{~m}$ sampai dengan $1.280 \mathrm{~m}$ diatas permukaan laut. Batas wilayah kecamatan Plaosan disebelah timur berbatasan dengan kecamatan Ngariboyo, sebelah selatan berbatasan dengan kecamatan Poncol, sebelah utara berbatasan dengan kecamatan Sidorejo, dan sebelah barat berbatasan dengan kabupaten Karanganyar Jawa Tengah. Kecamatan Plaosan terdiri dari 15 desa yang merupakan kecamatan terbesar kedua di kabupaten Magetan, dengan luas seluruh kecamatan Plaosan 66,09 Km2. Wilayah kecamatan Plaosan terletak didataran tinggi yang sangat cocok untuk pertanian dan sekaligus pariwisata. Tanaman hortikultura adalah jenis tanaman yang banyak dibudidayakan petani di Kecamatan Plaosan, Kabupaten Magetan., Kondisi geografis yang mendukung dan cocok untuk budidaya tanaman hortikultura di desa-desa di Kecamatan Plaosan. Komoditas utama yang banyak dibudidayakan adalah wortel, kubis tomat dan sayuran lainya. Berikut Peta Wilayah Studi pnelitian Kecamatan Plaosan, Kabupaten Magetan.

\section{Kajian Teori}

Wilayah adalah sebuah batasan ruang georafis tanpa batasan yang pasti, sedangkan region adalah ruang geografis yang menunjukkan keterlibatan ruang (spatial) dari beberapa daerah administratif, baik sebagian maupun seluruhnya (Abdurahman, 2005). Menurut Nachrowi dan Suhandojo (1999), terdapat tiga komponen wilayah yang harus diperhatikan dan disebut sebagai tiga pilar pengembangan wilayah yaitu sumberdaya alam, sumberdaya manusia dan teknologi. Dalam konteks pengembangan wilayah, Pengembangan wilayah semakin relevan dalam mengimplementasikan kebijakan ekonomi dalam aspek kewilayahan. Hoover dan Giarratani dalam Nugroho dan Dahuri, 2004, menyimpulkan tiga pilar penting dalam proses pembangunan wilayah, yaitu:

1. Keunggulan komparatif (imperfect mobility of factor). Pilar ini berhubungan dengan 
keadaan dtemukannya sumber-sumber daya tertentu yang secara fisik relatif sulit atau memiliki hambatan untuk digerakkan antar wilayah. Hal ini disebabkan adanya faktor-faktor lokal (bersifat khas atau endemik, misalnya iklim dan budaya) yang mengikat mekanisme produksi sumber daya tersebut sehingga wilayah memiliki komparatif. Sejauh ini karakteristik tersebut senantiasa berhubungan dengan produksi komoditas dari sumber daya alam, antara lain pertanian, perikanan, pertambangan, kehutanan, dan kelompok usaha sektor primer lainnya.

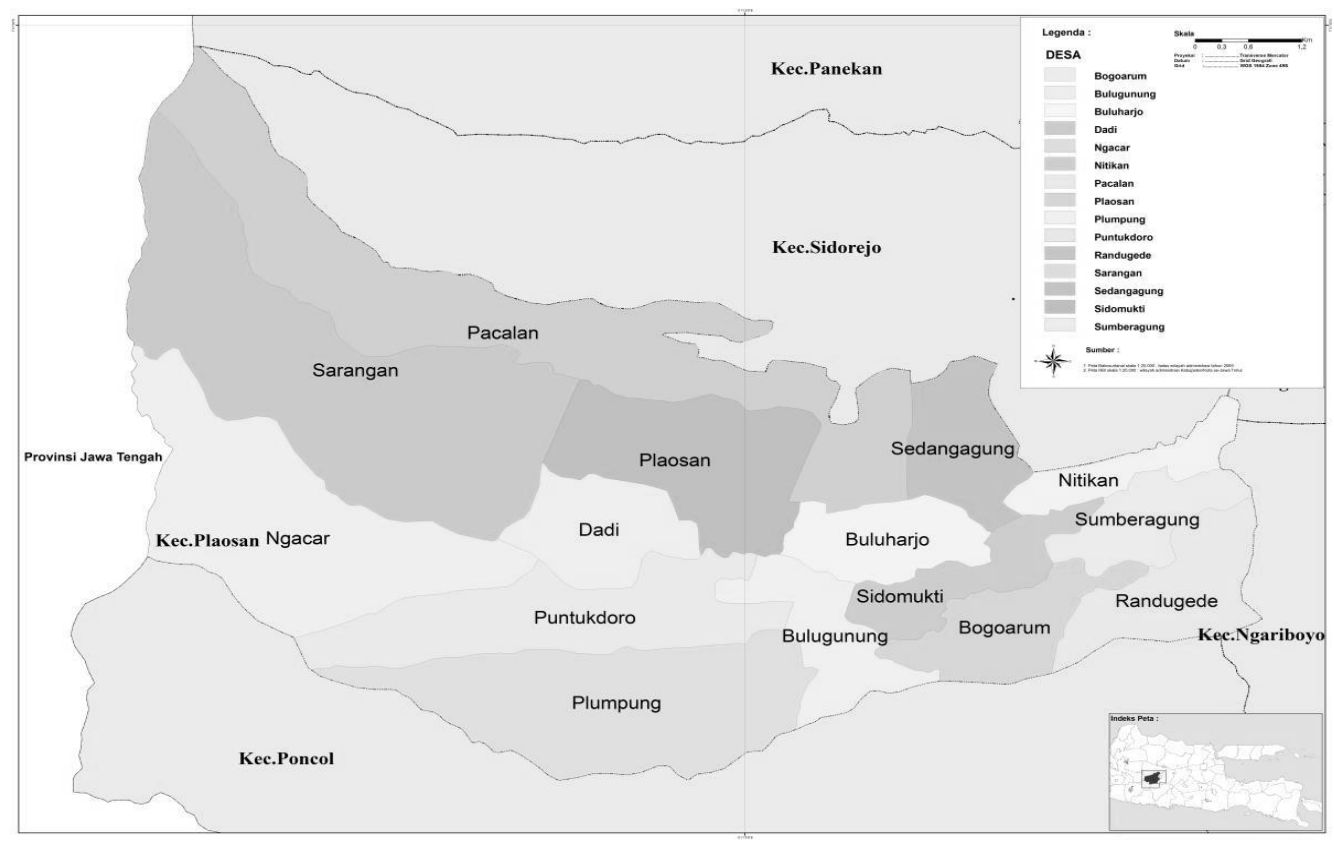

Sumber: Bappeda Kabupaten Magetan, 2012

\section{Gambar 1. Peta Wilayah Studi Penelitian}

2. Aglomerasi (imperfect divisibility). Pilar aglomerasi merupakan fenomena eksternal yang berpengaruh terhadap pelaku ekonomi berupa meningkatnya keuntungan ekonomi secara spasial. Hal ini terjadi karena berkurangnya biaya-biaya produksi akibat penurunan jarak dalam pengangkutan bahan baku dan distribusi produk.

3. Biaya transpor (imperfect mobility of good and service). Pilar ini adalah yang paling kasat mata mempengaruhi aktivitas perekonomian. Implikasinya adalah biaya yang terkait dengan jarak dan lokasi tidak dapat lagi diabaikan dalam proses produksi dan pembangunan wilayah

Salah satu model pengembangan wilayah berbasis pedesaan yang paling banyak dibicarakan adalah pengembangan agropolitan. Konsep pengembangan agropolitan muncul dari permasalahan adanya ketimpangan pembangunan wilayah antara kota sebagai pusat kegiatan dan pertumbuhan ekonomi dengan wilayah pedesaan sebagai pusat kegiatan pertanian yang tertinggal. Salah satu ide pendekatan pengembangan perdesaan adalah mewujudkan kemandirian pembangunan perdesaaan yang didasarkan pada potensi wilayah desa itu sendiri, dimana keterkaitan dengan perekonomian kota harus bisa diminimalkan (Pranoto, 2007). Secara tekstual, model ini pada dasarnya adalah membangun pusat pelayanan bagi pengembangan pertanian pada wilayah pertanianya itu sendiri, tidak pada wilayah perkotaan yang sudah berkembang (Setyono, 2007). 
Potensi perdesaan yang utama adalah sektor pertanian. Pertanian didefinisikan sebagai pengelolaan tanaman, ternak, ikan dan lingkungannya agar memberikan suatu produk (Mardjuki, 1994). Menurut Fatah (2006) faktor -faktor utama dalam pembangunan pertanian yang merupakan syarat mutlak yang harus ada untuk dapat berjalanya pembangunan pertanian adalah pasaran hasil produksi pertanian, teknologi yang senantiasa berubah, tersedianya sarana produksi secara lokal, perangsang produksi, dan pengangkutan.

\section{Analisis Karakterisitik dan Potensi Sektor Pertanian Hortikultura di Kecamatan Plaosan Kabupaten Magetan}

Didalam pembahasan ini terkait dengan analisis karakteristik dan potensi wilayah di Kecamatan Plaosan dilihat dari berbagai aspek antara lain ketersediaan atau luas lahan pertanian, tenaga kerja yang bekerja pada sektor pertanian, dan produktivitas sektor pertanian hortikultura itu sendiri selama beberapa tahun kebelakang. Berikut Tabel potensi lahan pertanian, dan penduduk yang bermata pencarian disektor pertanian di Kecamatan Plaosan.

Tabel 1. Luas Lahan Pertanian di Kecamatan Plaosan Kabupaten Magetan (Ha)

\begin{tabular}{|c|c|c|c|c|c|c|}
\hline \multirow[b]{2}{*}{ Desa } & \multicolumn{3}{|c|}{2008} & \multicolumn{3}{|c|}{2012} \\
\hline & Sawah & $\begin{array}{l}\text { Tegalan/ } \\
\text { lahan } \\
\text { kering }\end{array}$ & Jumlah & Sawah & $\begin{array}{c}\text { Tegalan/ } \\
\text { lahan } \\
\text { kering }\end{array}$ & Jumlah \\
\hline Ngancar & 0 & 137,90 & 137,90 & 0 & 135,82 & 135,82 \\
\hline Plumpung & 71,20 & 300,07 & 371,27 & 73,50 & 300,07 & 373,57 \\
\hline Puntukdoro & 90,56 & 134,12 & 224,68 & 90,36 & 134,17 & 224,53 \\
\hline Bulugunung & 111,62 & 74,00 & 185,62 & 110,62 & 74,00 & 184,62 \\
\hline Bogoarum & 86,9 & 88,06 & 174,96 & 83,15 & 87,09 & 170,24 \\
\hline Sumberagung & 97,76 & 2,38 & 100,14 & 94,84 & 4,30 & 99,14 \\
\hline Nitikan & 46 & 12,92 & 58,92 & 43,47 & 12,92 & 56,39 \\
\hline Sidomukti & 124,49 & 7,26 & 131,75 & 132,47 & 6,00 & 138,47 \\
\hline Buluharjo & 133,31 & 26,48 & 159,79 & 131,65 & 26,14 & 157,79 \\
\hline Plaosan & 105,28 & 172,90 & 278,18 & 105,28 & 172,79 & 278,07 \\
\hline Dadi & 69,61 & 217,03 & 286,64 & 60,96 & 217,00 & 277,96 \\
\hline Sarangan & 0 & 235,92 & 235,92 & 0 & 235,92 & 235,92 \\
\hline Pacalan & 118,57 & 207,82 & 326,39 & 116,62 & 210,39 & 327,01 \\
\hline Sendangagung & 51,31 & 11,64 & 62,95 & 51,31 & 11,64 & 62,95 \\
\hline Jumlah & 1106,61 & 1628,50 & 2735,11 & 1094,23 & 1628,25 & 2722,48 \\
\hline
\end{tabular}

Sumber: BPS Kab. Magetan 2009, 2012

Tabel 2. Komposisi Jumlah Penduduk yang Bermatapencaharian di Sektor Pertanian di Kecamatan Plaosan 2008 dan 2012

\begin{tabular}{l|l|l|l|l|l|l|l}
\hline \multirow{3}{*}{ No } & \multirow{2}{*}{ Desa } & $\begin{array}{l}2008 \\
\text { Petani } \\
\text { pemilik } \\
\text { Lahan }\end{array}$ & $\begin{array}{l}\text { Buruh } \\
\text { Tani }\end{array}$ & Jumlah & $\begin{array}{l}\text { Petani } \\
\text { pemilik } \\
\text { Lahan }\end{array}$ & $\begin{array}{l}\text { Buruh } \\
\text { Tani }\end{array}$ & Jumlah \\
\hline
\end{tabular}




\begin{tabular}{|c|c|c|c|c|c|c|c|}
\hline \multirow[b]{2}{*}{ No } & \multirow[b]{2}{*}{ Desa } & \multicolumn{3}{|l|}{2008} & \multicolumn{3}{|l|}{2012} \\
\hline & & $\begin{array}{l}\text { Petani } \\
\text { pemilik } \\
\text { Lahan }\end{array}$ & $\begin{array}{l}\text { Buruh } \\
\text { Tani }\end{array}$ & Jumlah & $\begin{array}{l}\text { Petani } \\
\text { pemilik } \\
\text { Lahan } \\
\end{array}$ & $\begin{array}{l}\text { Buruh } \\
\text { Tani }\end{array}$ & Jumlah \\
\hline 1 & Ngancar & 461 & 104 & 565 & 461 & 104 & 565 \\
\hline 2 & Plumpung & 707 & 269 & 976 & 1.204 & 188 & 1.392 \\
\hline 3 & Puntukdoro & 778 & 189 & 967 & 1.407 & 206 & 1.613 \\
\hline 4 & Bulugunung & 943 & 264 & 1.207 & 2.414 & 484 & 2.898 \\
\hline 5 & Bogoarum & 540 & 126 & 666 & 475 & 257 & 732 \\
\hline 6 & Sumberagung & 559 & 94 & 653 & 559 & 77 & 636 \\
\hline 7 & Nitikan & 436 & 60 & 496 & 301 & 101 & 402 \\
\hline 8 & Sidomukti & 659 & 287 & 946 & 727 & 287 & 1.014 \\
\hline 9 & Buluharjo & 778 & 361 & 1.139 & 1.092 & 210 & 1.302 \\
\hline 10 & Plaosan & 1.122 & 127 & 1.249 & 1.648 & 127 & 1.775 \\
\hline 11 & Dadi & 967 & 219 & 1.186 & 967 & 219 & 1.186 \\
\hline 12 & Sarangan & 733 & 160 & 893 & 432 & 204 & 636 \\
\hline 13 & Pacalan & 991 & 328 & 1.319 & 1.561 & 328 & 1.889 \\
\hline \multirow[t]{2}{*}{14} & Sendangagung & 372 & 233 & 605 & 372 & 290 & 662 \\
\hline & Jumlah & 10.046 & 2.821 & 12.867 & 13.620 & 3.082 & 16.702 \\
\hline
\end{tabular}

Sumber: BPS Kabupaten Magetan, 2012

Berdasarkan hasil analisis karakter dan potensi wilayah terkait dengan ketersediaan lahan pertanian, tenaga kerja, masihlah sangat potensial untuk dikembangkan. Lahan pertanian yang masih luas dimana selama tahun 2008 sampai dengan 2012 perubahan lahan pertanianya berkurang hanya $0,9 \%$. Hal ini mengindikasikan alih fungsi lahannya masih rendah. Tenaga kerja pada sektor pertanian ini juga masih sangat potensial dimana terjadi kenaikan sekitar 30\% jumlah petani di Kecamatan Plaosan Kabupaten Magetan selama kurun waktu 4 (empat) tahun antara tahun 2008 sampai tahun 2012. Hal tersebut menunjukan bahwa minat dari masyarakat untuk memilih sektor pertanian sebagai mata pencarian sangat besar. Jika dibandingkan dengan dinamika perubahan penduduk yang bekerja pada sektor pertanian secara nasional menyebutkan bahwa setiap tahunnya terjadi penurunan jumlah rumah tangga petani di Indonesia yaitu sekitar 1,75\%. Dilihat dari segi produktivitas pertanian holtikulura di Kecamatan Plaosan masihlah rendah dibandingkan dengan produktivitas rata-rata nasional untuk setiap 1000M2 lahan pertanian. Dimana hanya sekitar $75 \%$ rata-rata produktivitas sektor pertanian hortikultura di Kecamatan Plaosan terhadap rata-rata produktivitas nasional. Sehingga masih ada potensi untuk di maksimalkan produktivitas pertaniannya untuk menambah pendapatan dan kesejahteraan petani.

\section{Analisis Faktor-Faktor Pendorong dan Penghambat Didalam Pengembangan Wilayah yang Berbasis Sektor Pertanian Hortikultura di Kecamatan Plaosan}

Faktor pendorong dan penghambat yang menjadi variabel terpilih dalam penelitian ini yaitu kondisi sarana prasarana trasportasi, jaringan irigasi, pemasaran/pasar dan Ketersediaan bahan alat produksi secara lokal. Berdasarkan hasil penilaian petani di 14 (empat belas) desa di Kecamatan Plaosan rata-rata kondisinya secara umum sudah sesuai dengan kebutuhan petani. Dimana dalam penilaian kuisioner rata-rata adalah Baik. Dari sini didapatkan kesimpulan bahwa secara umum infrastruktur pendukung kegiatan 
pertanian di Kecamatan Plaosan sudah baik. Hal yang masih kurang dalam hal ini adalah terkait dengan ketersediaan bahan dan alat produksi secara lokal terutama kebutuhan bibit unggul yang masih menjadi permasalahan utama, obat dan pupuk yang terus naik. Pemasaran terkait dengan stabilitas harga produksi pertanian hortikultura yang masih belum stabil. Harga pada saat panen cenderung turun. Untuk jaringan irigasi pada umumnya sudah baik kususnya untuk lahan sawah. Akan tetapi masih banyak juga lahan kering yang belum dapat diakses jaringan irigasi sehingga belum dapat dimaksimalkan pertanian dilahan kering tersebut. Sedangkan untuk jaringan pengangkutan dalam hal ini jalan desa maupun jalan usaha taninya sudah baik.

\section{Analisis Pengaruh Kegiatan Pertanian Hortikultura Bagi Peningkatan Nilai Tukar Petani di Wilayah Kecamatan Plaosan}

Untuk mengetahui pengaruh kegiatan pertanian Hortikultura bagi kesejahteraan petani dapat dilakukan dengan salah satu metode perhitungan nilai tukar petani( NTP). Dimana NTP ini merupakan perbandingan indeks pendapatan dan indeks yang dibayar /pengeluaran petani pada masing-masing rumah tangga petani. Perhitungan ini dilakukan untuk menghitung pendapatan rumah tangga petani dan pengeluaran rumah tangga petani selama satu musim tanam atau setiap 3 (tiga) bulan. Hal dikarenakan masa tanam tanaman hortikultura rata-rata membutuhkan waktu selama 3 (tiga) bulan. Rumus perhitungan Nilai Tukar Petani adalah sebagai berikut:

$N T P=\frac{I_{t}}{I_{b}} \times 100 \%$

It : harga yang diterima petani

Ib : harga yang dibayar petani

NTP : nilai tukar petani

Tabel 3. Nilai Tukar Petani (NTP) di Kecamatan Plaosan dan Perbandingannya dengan Rata-rata NTP Nasional

\begin{tabular}{l|l|r|r|r}
\hline No & \multicolumn{1}{|c|}{ Desa } & $\begin{array}{c}\text { Nilai Tukar Petani } \\
(\text { NTP) }\end{array}$ & $\begin{array}{c}\text { NTP Rata-rata } \\
\text { Nasional }\end{array}$ & \multicolumn{1}{c}{ Ketarangan } \\
\hline 1 & Bogoarum & 102 & 109,34 & $-7,34$ \\
\hline 2 & Bulugunung & 100 & 109,34 & $-9,34$ \\
\hline 3 & Buluharjo & 96 & 109,34 & $-13,34$ \\
\hline 4 & Dadi & 94 & 109,34 & $-15,34$ \\
\hline 5 & Ngancar & 91 & 109,34 & $-18,34$ \\
\hline 6 & Nitikan & 93 & 109,34 & $-16,34$ \\
\hline 7 & Pacalan & 106 & 109,34 & $-3,34$ \\
\hline 8 & Plaosan & 115 & 109,34 & 5,66 \\
\hline 9 & Plumpung & 90 & 109,34 & $-19,34$ \\
\hline 10 & Puntukdoro & 96 & 109,34 & $-13,34$ \\
\hline 11 & Sarangan & 106 & 109,34 & $-3,34$ \\
\hline 12 & Sendangagung & 93 & 109,34 & $-16,34$ \\
\hline 13 & Sidomukti & 112 & 109,34 & 2,66 \\
\hline 14 & Sumberagung & 115 & 109,34 & 5,66 \\
\hline & Rata-Rata & 100,96 & 109,34 & $-8,74$ \\
\hline
\end{tabular}


Dalam perkembanganya kegiatan pertanian hortikultura berdasarkan hasil dari penelitian ini mengindikasikan bahwa kondisi saat ini kegiatan usaha pertanian tersebut masih belum memberikan pengaruh yang sangat besar bagi kesejahteraan petani di desadesa Kecamatan Plaosan dengan indikator Nilai Tukar Petani /NTP rata-rata di 14 (empat belas) desa di Kecamatan Plaosan adalah 100,96. Nilai NTP sektor pertanian hortikultura di Kecamatan Plaosan ini masih jauh dari rata-rata NTP sektor pertanian hortikultura nasional yaitu sebesar 109,34. Masih terdapat selisih rata-rata NTP sektor pertanian hortikultura di Kecamatan Plaosan dengan rata-rata NTP Sektor pertanian hortikultura nasional yaitu 8,74. Dengan nilai NTP sebesar 100,96 tersebut mengindikasikan bahwa kegiatan sektor pertanian ini masih berada pada titik impas belum memberikan kesejahteraan maksimal kepada petani.

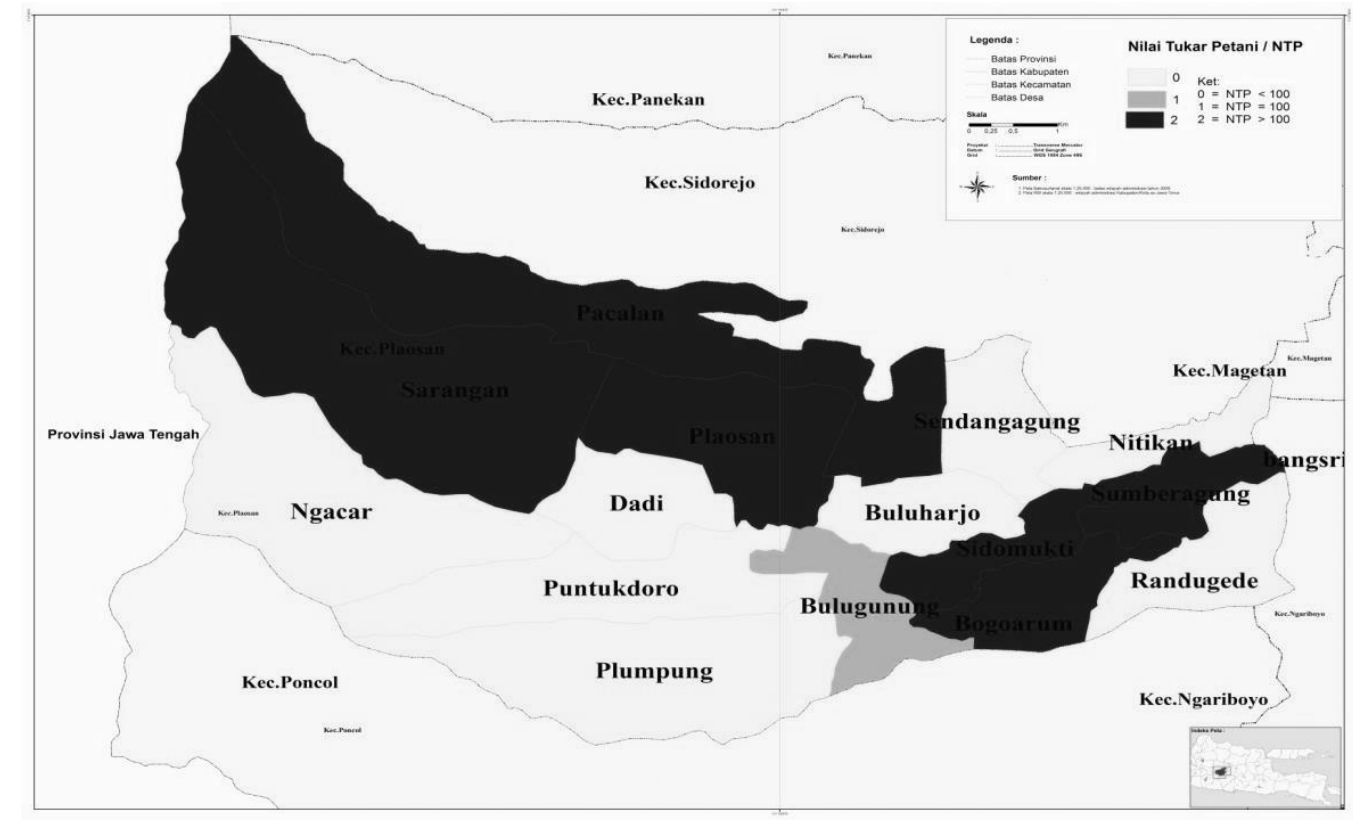

Gambar 2. Peta Persebaran NTP Desa-desa di Kecamatan Plaosan

Berdasarkan analisis regresi berganda untuk mengetahui pengaruh keempat variabel yaitu transportasi, irigasi, pemasaran/pasar, ketersediaan bahan dan alat didapatkan pengaruh keempat variabel tersebut terhadap NTP petani dimana dari keempat variabel tersebut yang paling berpengaruh adalah ketersediaan bahan dan alat secara lokal. Kemudian, pemasaran/pasar, kondisi Irigasi dan trasportasi. Untuk trasportasi sendiri dalam analisis ini tidak berpengaruh secara signifikant terhadap hasil NTP petani dikarenakan kondisi jalan/ trasportasi pada setiap desa di Kecamatan Plaosan hampir semuanya sudah bagus dan tidak dipermasalahkan oleh petani. Kemudian berdasarkan Tabel model Summary terdapat R square sebesar 0.823 dalam hal ini berarti $82,3 \%$ kontribusi keempat variabel tersebut terhadap hasil NTP petani. Sedangkan sisanya dapat dipengaruhi oleh sebab lainya. Dari hasil hitung regresi berganda variabel terikat Y (NTP) terhadap variabel bebas X1 (transportasi), X2 (kondisi irigasi), X3 (pemasaran/pasar), X4 (ketersediaan bahan dan alat) dapat dirumuskan persamaan regresi bergandanya sebagai berikut: 
$\mathrm{Y}=\mathrm{a}+\mathrm{b} 1 \mathrm{X} 1+\mathrm{b} 2 \mathrm{X} 2+\mathrm{b3X3}+\mathrm{b} 4 \mathrm{X} 4$

$Y=-97,395+0,043 X 1+0,194 X 2+0,330 X 3+0,570$

$\mathrm{Y}=$ Nilai tukar petani (NTP)

$\mathrm{a}=$ Konstanta

$\mathrm{X} 1=$ Trasportasi

$\mathrm{X} 2=$ Kondisi irigasi

$\mathrm{X} 3=$ Pemasaran $/$ pasar

$\mathrm{X} 4=$ Ketersediaan bahan dan alat

Konstanta sebesar - 97,395 adalah apabila variabel bebasnya (X) bernilai 0 maka nilai NTP adalah -97,395. Koefisien X1( trasportasi) sebesar 0,043 adalah setiap penambahan (karena tanda + ) satu nilai/skor variabel trasportasi maka akan memberikan peningkatan skor sebesar 0,043. Koefisien X2 (kondisi irigasi) sebesar 0,194 adalah setiap penambahan (karena tanda + ) satu nilai kondisi irigasi akan memberikan peningkatan skor sebesar 0,194. Koefisien X3 (pemasaran/pasar) sebesar 0,330 adalah setiap penambahan (karena tanda + ) satu nilai /skor pemasaran/pasar akan memberikan peningkatan skor sebesar 0,330. Koefisien X4 (ketersediaan bahan dan alat) sebesar 0,570 adalah setiap penambahan ( karena tanda + ) satu nilai /skor variabel ketersediaan bahan dan alat maka akan memberikan peningkatan skor sebesar 0,570.

Untuk itulah yang perlu diperhatikan disini adalah pertama, ketersediaan bahan dan alat secara lokal yang mana dalam hal ini terutama adalah benih unggul, pupuk, obatobatan. Kedua, terkait pemasaran/pasar dimana permasalahanya terutama pada harga pada saat musim panen yang cenderung turun apabila panenya sebagaian besar berhasil. Artinya ketika panen melimpah harga relatif turun akan tetapi ketika panen kurang baik hasilnya, harga cenderung naik. Permasalahan tersebut menyebabkan petani kurang menikmati hasil panen yang didapat. Perlu adanya kebijakan stabilitas harga ditingkat petani dimana peran pemerintah daerah dan pusat disini sangat menentukan dalam hal kebijakan stabilitas harga. Ketiga, terkait dengan kondisi Irigasi, meskipun sebagaian besar petani berpendapat bahwa kondisi irigasi di desa mereka sudah bagus dimana kebutuhan pengairan tercukupi pada lahan sawah mereka. Namun untuk beberapa lahan kering masih ada yang kesulitan mendapatkan irigasi. Jangkauan irigasi yang dapat melayani lahan kering ini sudah diupayakan dengan sistem irigasi springkler. Namun demikian belum semua lahan kering terpasang jaringan irigasi Springkler. Oleh karena itu perlu diupayakan untuk memperluas jaringan irigasi genangan maupun springkler ke lahan-lahan kering yang belum terjangkau saluran irigasi.

\section{Kesimpulan}

Dari hasil penelitian dan pembahasan terkait pengembangan wilayah berbasiskan subsektor pertanian hortikultura di Kecamatan Plaosan Kabupaten Magetan dapat ditarik kesimpulan bahwa pengembangan wilayah berbasis sektor pertanian hortikultura di Kecamatan Plaosan Kabupaten Magetan tersebut dilihat dari karakteristik dan potensi wilayahnya sangat mungkin dan layak untuk dikembangkan. Hal ini karena daerah tersebut memiliki karakterisitik dan potensi yang sangat mendukung kegiatan sektor pertanian hortikultura dimana sektor ini akan menjadi motor penggerak pembangunan ekonomi wilayah di daerah tersebut. Pembangunan wilayah yang didasarkan pada potensi dan karakteristik wilayah akan memberikan dampak maskimal dan hasil yang optimal bagi masyarakat di wilayah tersebut. Namun demikian sat ini kegiatan pertanian hotikultura di 
Kecamatan Plaosan belum memberikan hasil yang optimal bagi kesejahteraan petani dimana nilai tukar petani (NTP) nya masih dibawah rata-rata NTP nasional. Dari hasil perhitungan analisis regresi berganda empat variabel yaitu, trasnsportasi, irigasi, pemasaran/pasar dan ketersediaan bahan dan alat secara lokal, menunjukan bahawa faktor ketersediaan bahan dan alat secara lokal memiliki pengaruh yang paling sangat signifikant terhadap hasil nilai tukar petani (NTP). Ketersediaan bahan dan alat secara lokal sangat menetukan produktivitas pertanian yang berdampak langsung pada hasil pendapatan petani. Hal ini menunjukan perlu adanya upaya untuk mengatasi permasalahan ketersediaan bahan dan alat secara lokal di desa-desa Kecamatan Plaosan.

\section{Rekomendasi}

Dari kesimpulan diatas yang menyatakan bahwa Kecamatan Plaosan memiliki karakterisitik dan potensi wilayah yang mendukung kegiatan pertanian Hortikultura. Sektor pertanian hortikultura ini dapat dikembangkan dan menjadi motor penggerak perekonomian masyarakat serta menjadi leading sector yang mendorong pembangunan wilayah di Kecamatan Plaosan. Namun dalam perkembangannya sektor ini belum memberikan kontribusi yang maksimal bagi peningkatan pendapatan dan kesejahteraan masyarakat. Hal tersebut dibuktikan dengan Nilai rata-rata NTP petani yang masih rendah dibandingkan rata-rata NTP petani secara Nasional. Untuk itulah rekomendasi didalam upaya peningkatan NTP Petani, pengoptimal kinerja sektor pertanian Hortikultura adalah sebagai berikut:

1. Pembenahan subsektor hulu petanian hortikultura di Kecamatan Plaosan. Dalam hal ini terkait dengan penyediaan bibit unggul, pupuk, obat-obatan. terutama bibit unggul seperti kentang, dan bawang merah yang belum dapat disediakan secara lokal. Kedua komoditas tersebut harus didatangkan dari daerah lain seperti kentang dari Bandung, dan Dieng, untuk bawang merah masih didatangkan dari Brebes. Selain itu penyediaan dan perbaikan kualitas bibit unggul komoditas-komoditas yang ditanam petani juga harus ditingkatkan. Pembangunan sentra pembenihan bibit unggul di Kecamatan Plaosan dibutuhkan untuk memenuhi kebutuhan bibit petani dengan kualitas unggul. Bibit pertanian ini menjadi salah satu permasalahan masih rendahnya tingkat produktivitas pertanian di daerah ini.

2. Pembenahan subsektor primer pertanian hortikultura dalam hal ini terkait dengan kegiatan pertanian. Pola bercocok tanam yang baik dan pemilihan komoditas yang memiliki nilai ekonomis tinggi juga merupakan salah satu alternatif peningkatan pendapatan petani. Dibutuhkan juga pendampingan dari penyuluh pertanian yang profesional yang dapat memberikan pendampingan kepada petani secara baik untuk mengatasi permasalahan-permasalahan di lapangan yang dihadapi petani.

3. Pembenahan subsektor hilir pertanian hortikultura terkait dengan pergudangan, pengolahan, dan distribusi komoditas pertanian, serta berbagai produk yang dihasilkan dari komoditas pertanian. Dimana nantinya hasil pertanian yang dihasilkan dapat diolah agar memberikan nilai ekonomis yang lebih tinggi. Seperti bawang merah yang dapat dikeringkan dan disimpan untuk dijual pada saat harga naik, kentang yang bisa diolah menjadi produk makanan dan sebagainya dimana kegiatan ini dapat meningkatkan kesejahteraan petani.

4. Peningkatan subsektor jasa penunjang. Subsektor penunjang ini terkait dengan kegiatan yang menghasilkan dan menyediakan jasa yang dibutuhkan seperti pemasaran, irigasi, transportasi, penelitian pengembangan, penyuluhan dan konsultasi. Pembangunan subsektor penunjang ini diharapkan dapat meningkatkan produktivitas pertanian dan nilai tambah sektor pertanian yang berdampak pada peningkatan kesejahteraan petani. 


\section{Daftar Pustaka}

Abdurahman, Benjamin. 2005. Pemahaman Dasar Regional Management dan Regional Marketing, IAP Jawa Tengah dan Program Pascasarjana Universitas Diponegoro Semarang.

BPS, Kabupaten Magetan. 2011. Kecamatan Plaosan Dalam Angka.

Fatah, Luthfi. 2006. Dinamika Pembangunan pertanian Pedesaan. Pustaka Buana. Banjarbaru, Kalimantan Selatan.

Mardjuki, Asparno. 1994. Pertanian dan Masalahnya. Yogyakarta: Penerbit Andi Offset

Nachrowi ND, Suhandojo. 1999. Analisis Sumberdaya Manusia, Otonomi Daerah dan Pengembangan Wilayah. Di Dalam Tiga Pilar pengembangan Wilayah, Sumberdaya Alam, Sumberdaya Manusia, Teknologi. Pusat Pengkajian Kebijaan Teknologi Pengembangan Wilayah, BPPT. Jakarta.

Norton, Roger D. 2004. Agricultural Development Policy, Concepts and Experiences. John Wiley \& Sons Ltd, The Atrium, Southern Gate, Chichester, West Sussex PO19 8SQ, England

Nugroho, Iwan dan Rochmin Dahuri. 2004. Pembangunan wilayah, Perspektif Ekonomi, Sosial dan lingkungan. Jakarta: Pustaka LP3ES

Setyono, J. 2007. Pengantar Perencanaan Wilayah Dan Kota. Universitas Diponegoro. Semarang.

Supranto, J. 2010. Analisis Multivariat, Arti dan interpretasi. Jakarta: Rineka Cipta

THE WORLD BANK. 2008. Agriculture for Development. world development report 2008. The International Bank for Reconstruction and Development / The World Bank.

Wahana Komputer. 2010. Mengolah data statistik, hasil penelitian dengan SPSS 17. Yogyakarta: Andi

Ambardi, UM dan Prihawantoro (Ed). 2002. Pengembangan Wilayah dan Otonomi Daerah. Jakarta : Pusat Pengkajian Kebijakan Teknologi Pengembangan Wilayah Deputi Pengkajian Kebijakan Teknologi BPPT.

Rustiadi, E. dan S. Pranoto. 2007. Agropolitan Membangun Ekonomi Perdesaan. Cetakan Pertama. Crestpent Press. Bogor. 
54 Pengembangan Wilayah Berbasis Subsektor Pertanian Hortikultura Di Kecamatan Plaosan

JURNAL WILAYAH DAN LINGKUNGAN, 2 (1), 43-54 